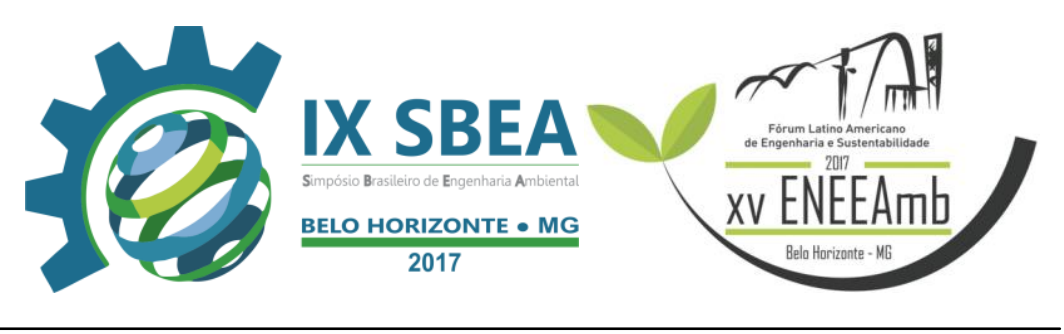

EDUCAÇÃO AMBIENTAL

\title{
EDUCAÇÃO AMBIENTAL VOLTADA A \\ CRIANÇAS DE UMA ESCOLA NO MUNICÍPIO DE PATOS DE MINAS - MG
}

Laís Ferreira Caixeta - lais.caixeta@outlook.com

Centro Universitário de Patos de Minas - UNIPAM

André Luiz Ramos - andreluizengamb@ gmail.com

Centro Universitário de Patos de Minas - UNIPAM

Débora Clarisa Teles - deborateles.engamb@gmail.com

Centro Universitário de Patos de Minas - UNIPAM

Larissa Cristina Ribeiro Porto - larissa.porto.engamb@ gmail.com

Centro Universitário de Patos de Minas - UNIPAM

Sthéferson Bruno da Silva - sthefersonbrunoam @ gmail.com

Centro Universitário de Patos de Minas - UNIPAM

Regina Célia Gonçalves - reginacelia@ unipam.edu.br

Centro Universitário de Patos de Minas - UNIPAM 


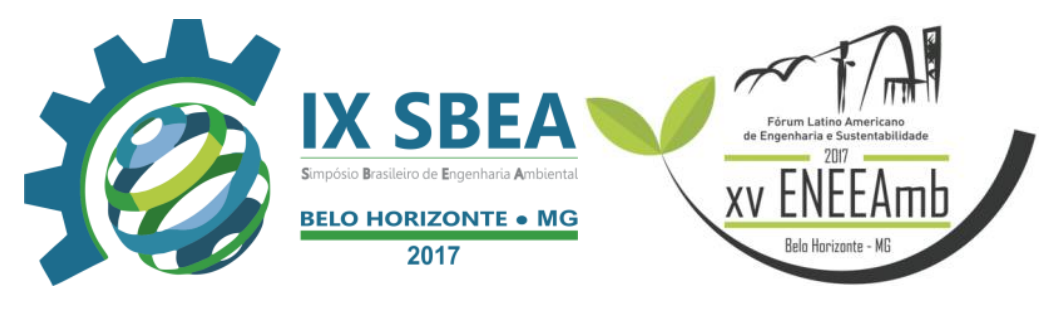

\section{RESUMO}

A globalização e o avanço da tecnologia estão contribuindo efetivamente para o aumento da poluição e o consumo errôneo dos recursos naturais. $\mathrm{O}$ destino incorreto dosresíduos sólidoscausa impactos negativos como problemas sociais e ambientais.A Educação Ambiental é utilizada como instrumento para agregar valores e conhecimentos ao público infantil, visando o equilíbrio do ser humano e o meio ambiente. $\mathrm{O}$ presente estudo mostra o resultado de atividades realizadas com alunos dasegunda série do ensino fundamental da Escola Estadual Adelaide Maciel no município de Patos de Minas-MG. As atividades foram realizadasno período de uma semana abordando os seguintes assuntos: uso de materiais recicláveis, destino correto dos resíduos sólidos, contato com a natureza e consumo inteligente. As crianças mostraram-se participativas e valorizaram o trabalho desenvolvido, podendo assim, compartilhar o conhecimento com seus familiares durante sua rotina diária. $\mathrm{O}$ jardim suspenso serviu como aprendizado de quão simples e divertido é produzir uma horta em uma residência,principalmente para o público infantil. $\mathrm{O}$ conhecimento agregado sobre resíduos sólidos possibilitou nos alunos uma reflexão sobre o consumo consciente e maneiras de contribuir para diminuição de resíduos e limpeza dos ambientes.

Palavras-chave: educação ambiental, resíduos sólidos, ensino fundamental, Patos de Minas - MG.

\section{INTRODUÇÃO E OBJETIVO}

O lixo é uma grande diversidade de resíduos de diferentes procedências. Dentre os resíduos que compõe essa diversidade, o sólido urbano gerado é um dos que apresenta maior volume de produção já que ocorre diariamente em residências e comércios, assim fazendo parte da história do homem, já que sua produção é inevitável (FADINI et al., 2001).

Segundo Phipippi Jr; Pelicioni (2005), a sociedade capitalista urbanoindustrial e seu atual modelo de desenvolvimento econômico e avanço tecnológico têm causado crescentes impactos sobre o ambiente. Tais impactos, na maioria das vezes, negativos, refletem no resultado do crescimento do processo de urbanização desordenado, assim como da precariedade dos serviços de coleta oferecidos pelo poder público, além da falta de informações oferecidas as pessoas que sofrem com uma infraestrutura inadequada (CARDOSO; SILVA, 2011).

Com o passar dos anos, a humanidade além de perceber, começou a se preocupar com a questão de sustentabilidade para as novas gerações. Este crescente interesse evidencia a importância do papel desempenhado pela educação ambiental, que 


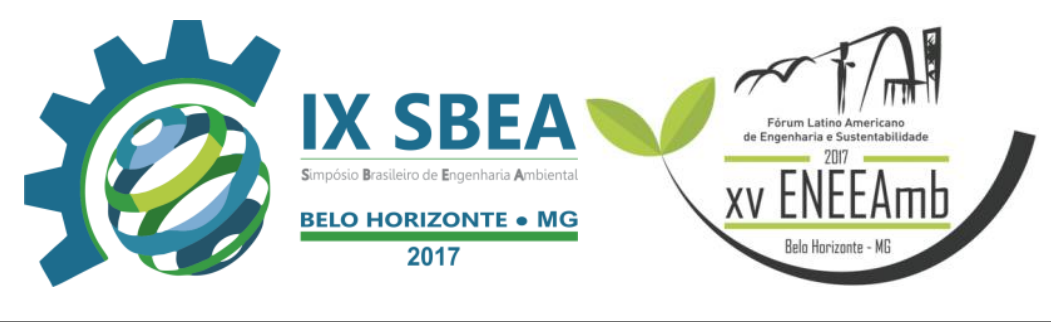

e de extrema importância na formação dos cidadãos, ajudando a desempenhar um conhecimento crítico, cultural e social, impactando de forma significativa as ações da sociedade (MACEDO; RAMOS, 2015).

KristenBailey (2015) cita que atualmente uma boa parcela das crianças no mundo, consomem produtos e recursos naturais sem ter qualquer ideia das consequências do potencial de impacto relacionado à sua utilização. E notório a necessidade de ensinar e mostrar às crianças que todos os recursos têm um impacto potencial no planeta, assim ensinado os bons hábitos, elas passarão a agir naturalmente como se fossem natose serão diligentes na sua implementação no cotidiano.

De acordo com Marçal (2005), os alunos do ensino fundamental devem receber um espaço privilegiado para as discussões socioambientais como carga horária oferecidas pelas escolas, pois nesta faixa etária os conhecimentos adquiridos influenciam diretamente nas mudanças de valores pessoais dos alunos em busca de atitudes que se ajustem à realidade. Dessa forma, o conhecimento que a criança obtiver será alicerce para suas ações futuras.

Observando a necessidade da educação ambiental, e sabendo de sua importância como uma das chaves para um futuro sustentável, este projeto tem como objetivo agregar e incitar conhecimento aos alunos da segunda sériedo ensino fundamental da Escola Estadual Adelaide Maciel no Município de Patos de Minas MG.

\section{METODOLOGIA}

O estudo foi realizado na Escola Estadual Adelaide Maciel situada na cidade de Patos de Minas - MG, localizada nas coordenadas Latitude 18³6'23.13"S e Longitude $46^{\circ} 31^{\prime} 06.45^{\prime \prime} \mathrm{W}$. Para a realização do estudo foi selecionado um público alvo que constitui de alunos da segunda série do ensino fundamental, visto que estes estão na faixa etária ideal para receber a metodologia proposta pelo trabalho.

Sabendo que a grande geração de resíduos sólidos na instituição é um problema, foram trabalhados métodos para conscientização das crianças, para refletir na 


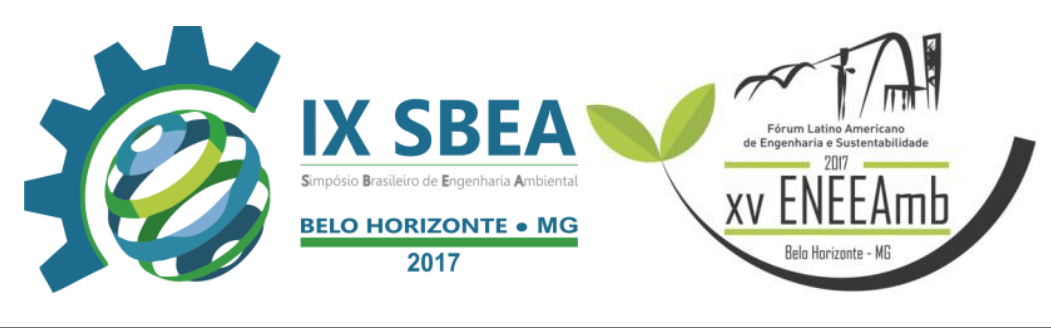

redução direta dos resíduos nesta escola. Mostrando que é possível evitar o acúmulo deresíduos e assim reduzir os impactos ambientais.

Foram escolhidas duas turmas de 28 alunos em cada sala, a idade destes alunos oscila entre os sete e oito anos.Contamos com um período de uma semana para a realização do projeto, que teve auxilio direto dos colaboradores da escola, onde os mesmos participaram das atividades abordadas alémacrescentarem sugestões validas ao contexto abordado.

O período escolhido para início das atividades foi no dia 30 de maio de 2016, ondeos coordenadores do projeto se apresentaram, propondo as atividades e explicando a forma em que as mesmas seriamrealizadas. A forma inicial foi uma apresentação aos alunos para conhecer os mesmos. Após a apresentação foi solicitado um feedback dos envolvidos para avaliar, a adesão do projeto, sendo bem avaliada de forma totalitária pelos colaboradores.

No segundo dia convidamos um policial militar para promover uma palestra para os alunos com o tema: Conservação do Meio Ambiente. Posteriormente a essa atividade, o grupo realizador do projeto fez um debate dinâmico com os discentes sobre resíduos sólidos. Nesta atividade questões foram abordadas e os alunos que responderam corretamente eram premiados.

No terceiro dia de realização do projeto de educação ambiental, foi trabalhado com os alunos um concurso de arte, no qual as crianças fizeram desenhos relacionados com as palestras ministradas no dia anterior. Foram escolhidos dois alunos vencedores de cada sala.

No quarto dia de projeto, os alunos foram levados para a sala de vídeo e assistiram animação infantil chamada "Turma da Mônica: Um plano para salvar o planeta". O filme era voltado para a limpeza do meio ambiente que vivemos, e as crianças puderam refletir sobre problemas que são enfrentados diariamente como a poluição dos rios, os desmatamentos, as queimadas e os resíduos gerados nas cidades. A animação também mostrou os alunos a importância da coleta seletiva, e dos três R's (reduzir, reutilizar e reciclar).

No quinto dia as crianças participaram de uma gincana proposta pelo grupo organizador, essa gincana foi totalmente voltada para o tema "redução de resíduos e 


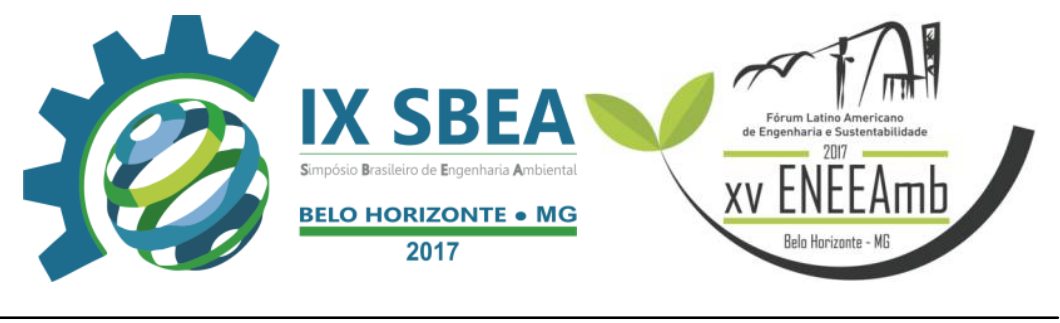

coleta seletiva". Os alunosforam divididos em quatro times (amarelo, azul, verde e vermelho). As tarefas desenvolvidas foram: competição limpeza diária das salas de aula, levar o maior número de garrafas pet para a escola, recolher o maior número de resíduos do pátio da instituição e a separação de resíduos recicláveis em suas devidas lixeiras.

No sexto e último dia de atividades, foi apresentado aos alunos um jardim vertical montado nas paredes do prédio da escola utilizando garrafas petde dois litros, feito pelos coordenadores do projeto. Estas garrafas foram trazidas pelos alunos dassuas residências. As crianças ajudaram no processo de plantio mudas cedias pelo IEF no jardim suspenso onde às mesmas tem a interação de regar estas plantas.

\section{RESULTADOS E DISCUSSÃO}

Na palestra inicial para a exposição do tema,a diversão e comprometimento das crianças foi algo exemplar. Participaram ativamente das palestras ministradas, uma grande parcela dos alunos respondeu o questionário de forma correta e foram presenteados. Conforme a figura 1 observam-se as crianças participando da palestra demonstrando empolgação nas respostas.

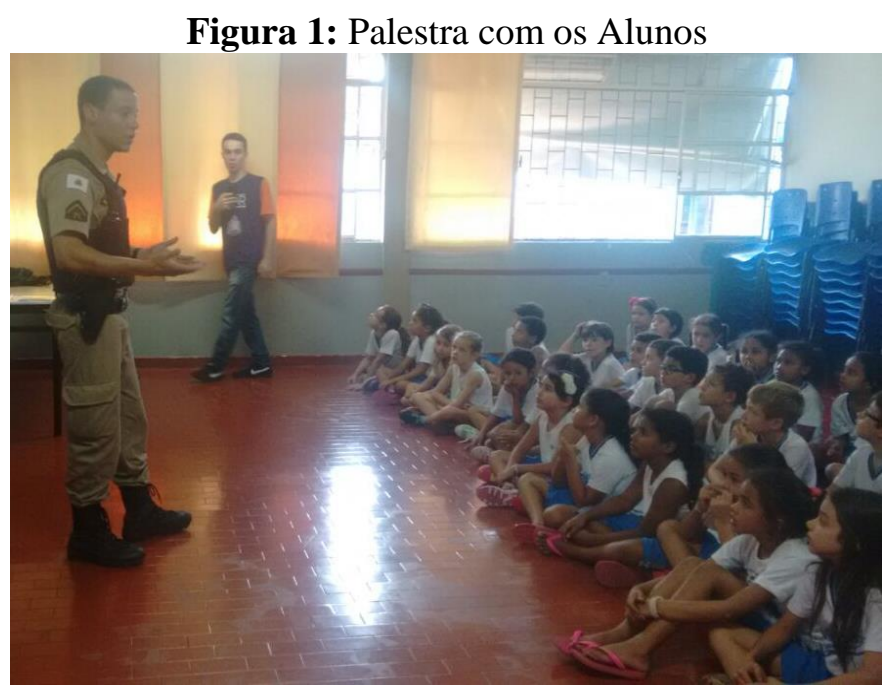

Fonte: Acervo dos Autores 


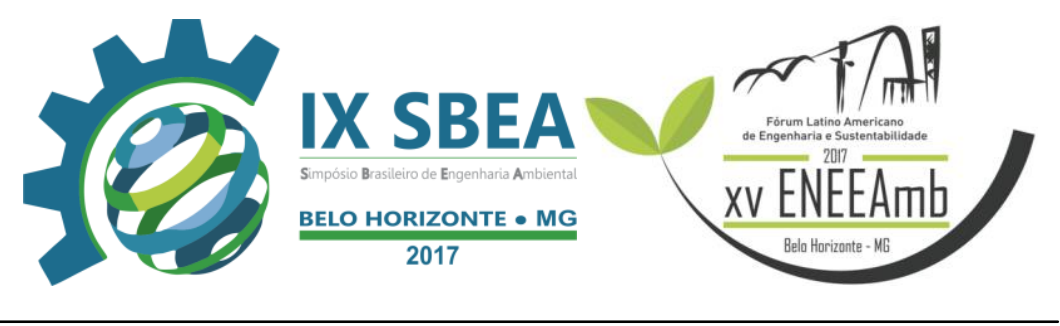

Segundo Andrade (2000) um bate papo com crianças tem principal meta, o desafio das mudanças de comportamento em relação ao meio ambiente, tendo impacto significativo na formação do ser humano.

$\mathrm{Na}$ segunda atividade as crianças realizaram um desenho que mostre o aprendizado adquirido durante a palestrada aula anterior conforme a figura 2. Em cada sala foram escolhidos dois desenhos que retrataram da melhor forma o assunto discutido na palestra.

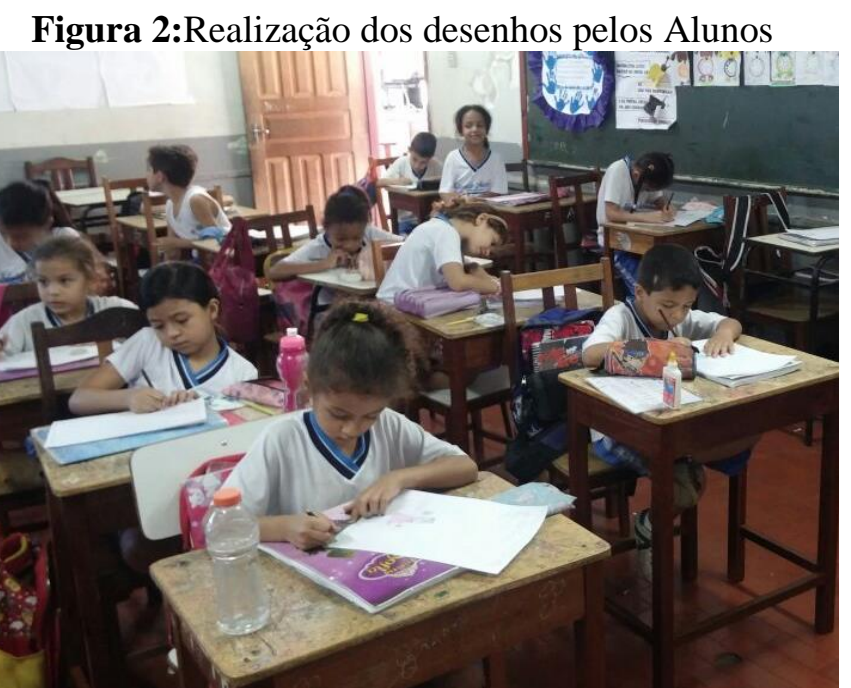

Fonte: Acervo dos Autores

As crianças têm suas próprias impressões, ideias e interpretações sobre a produção de arte e o fazer artístico, suas construções são elaboradas a partir de suas experiências ao longo da vida, por isso as crianças exploram, sentem, agem, refletem, e elaboram sentidos de suas experiências, construindo dessa forma pilares para suas atitudes em relação aos resíduos sólidos e a conservação dos recursos naturais através da arte. (BRASIL, 2013)

$\mathrm{Na}$ terceira atividade foi passado um vídeo que instigou a parte reflexiva dos alunos, trazendo novos conhecimentos, pois ficou nítido atenção das crianças pela animação apresentada figura 3 . 


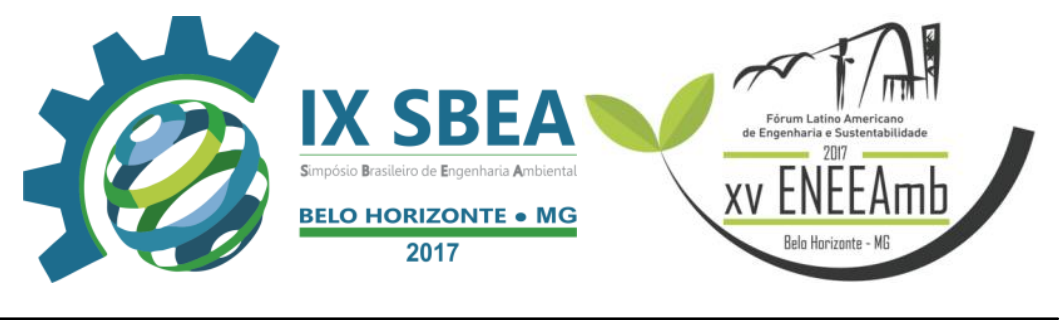

Figura 3:Vídeo aula apresentada aos alunos.

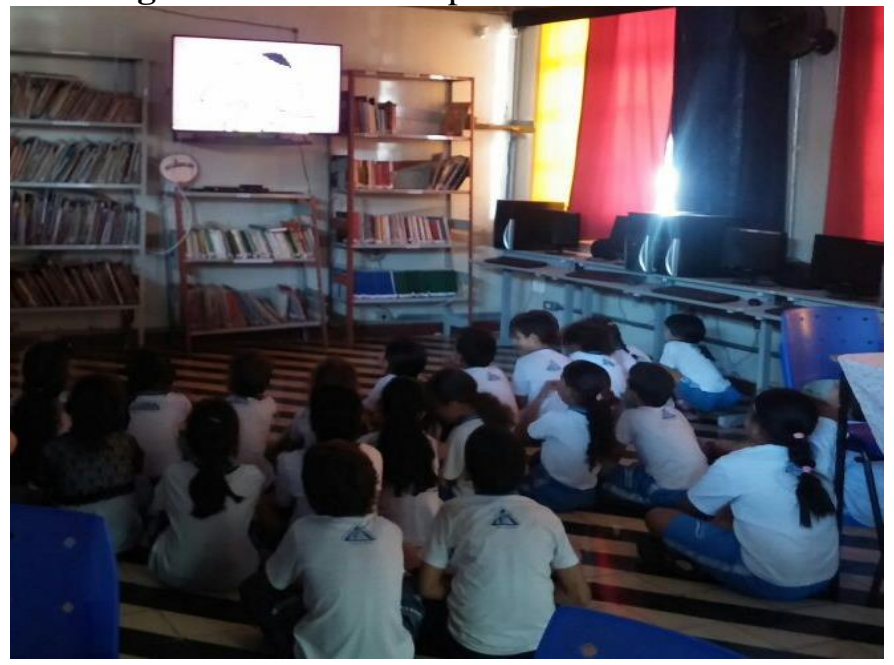

Fonte: Acervo dos Autores

Salgado, Pereira e Souza (2005) cita que vale convir que utilizando coerentemente os desenhos animados no ambiente escolar é possível transformar uma aula tradicional em uma aula interativa fazendo com que os alunos comentem sobre o assunto e correlacionem as suas atividades diárias, surgindo o espirito de mudança nas pequenas atitudes que envolvem o meio ambiente. Além de prepará-los para uma visão crítica e reflexiva da sua realidade como um todo.

Para a realização da quarta atividade foi utilizada a aplicabilidade do conhecimento em sala em forma de brincadeiras que trouxe à tona a real preocupação com o excesso de resíduos no ambiente escolar. Onde passamos tarefas para as crianças em forma de uma competição saldável.

Figura 4:Atividade em forma de Brincadeiras.

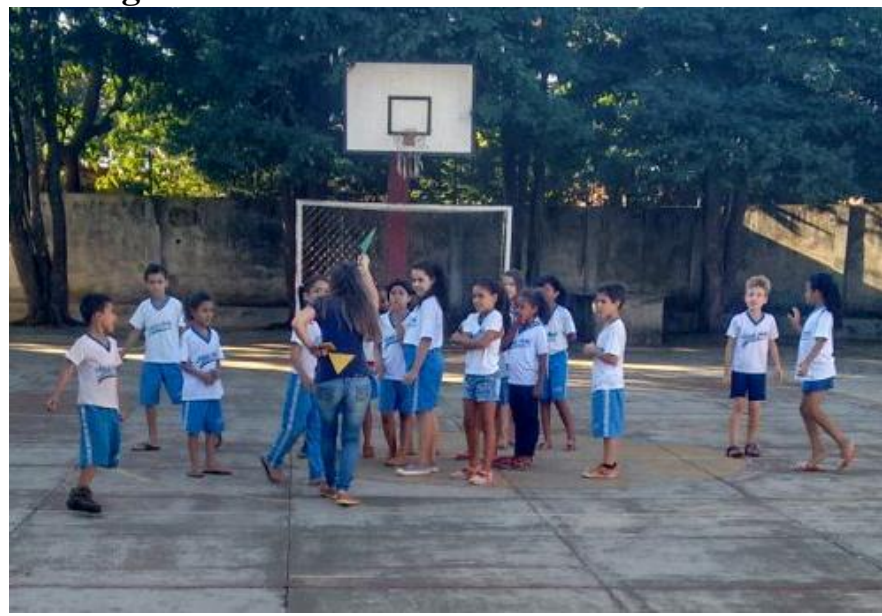

Fonte: Acervo dos Autores 


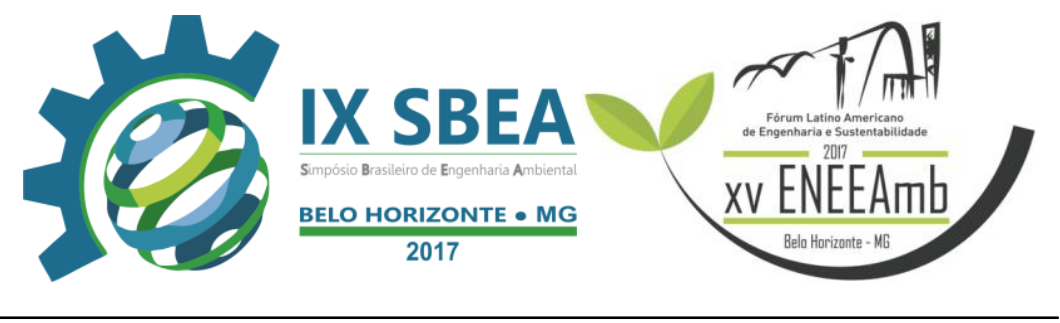

A atitude dos alunos diante as brincadeirasrelacionadas ao meio ambiente, ajuda na reflexão diante a comunidade, refletindo assim, sobre suas atitudes. Fazendo repensar seu papel diante da sociedade e do meio em que vivem. Fazendo com que as crianças tenham mais qualidade de vida sem desrespeitar o meio ambiente (FRIEDRICH, 2014).

Completando o ciclo de atividades, os alunos participaram do plantio de mudas em um jardim vertical, comemorandoo dia Mundial do Meio Ambiente. A alegria em participar do evento estava estampada no rosto dos participantes, unindo o aprendizado com diversão.Agregando conhecimento de uma forma simples que eles levam para suas residências.

Figura 5:Plantio de mudas junto aos alunos.

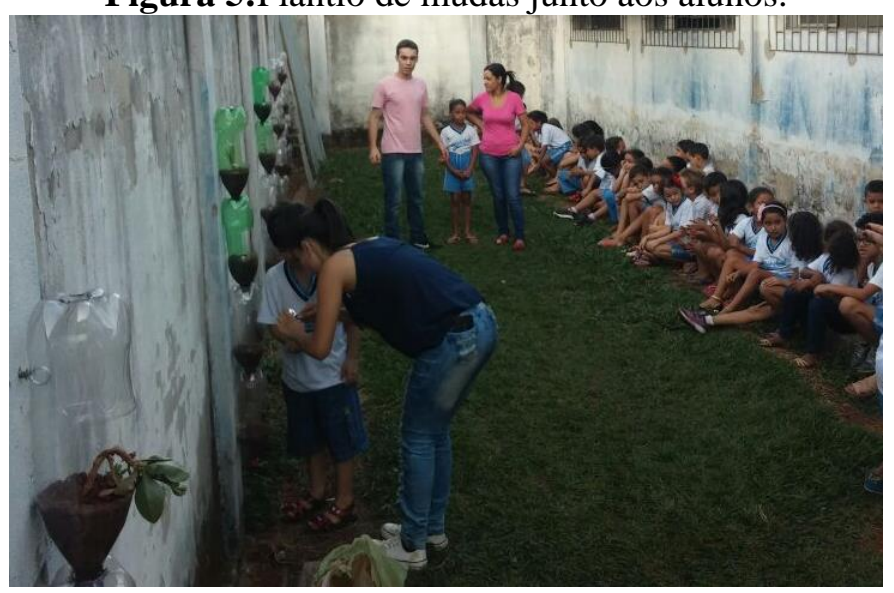

Fonte: Acervo dos Autores

Segundo Souza (2014) este trabalho visa o aproveitamento das garrafas pet que causariam danos ambientais se descartadas no lixo doméstico. Mostrando uma das diversas formas de reciclagem do material, assim moldando a forma de pensar das crianças. Através da reciclagem, consegue-se poupar e preservar os recursos naturais, além de reduzir os problemas ambientais, assim como os socioeconômicos decorrentes do descarte inadequado de resíduos sólidos (PIVA; WIEBECK, 2004). 


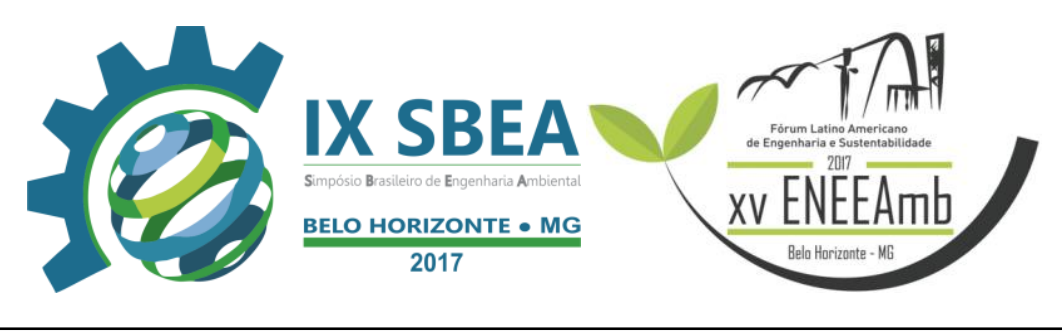

\section{CONCLUSÃO/RECOMENDAÇÕES}

O trabalho foi direcionado especialmente as crianças já que elas estão em fase de desenvolvimento, na faixa etária ideal para se aprender, sendo destacado que estas crianças serão o futuro do nosso planeta.

I. Observou-se aptidão de aprendizado das crianças pelos métodos trabalhados.

II. As atividades proporcionaram as criançasum conhecimento reflexivo quanto às questões da educação ambiental.

III. Pode-se destacar que a Educação Ambiental tem a capacidade de promover valores, não sendo somente um meio de transmitir informações.

Como sugestão que pode ser adotada pelo MEC ou secretarias de ensino, um programa de educação ambiental com maior periodicidade de aplicação nas escolas pode ser adotado na grade curricular haja vista que é notório o resultado positivo de inserções pontuais de conhecimento ambiental do projetodesenvolvido. Dessa forma um grande público seria atingido, gerando benefícios para toda sociedade.

\section{REFERÊNCIAS BIBLIOGRÁFICAS}

ANDRADE, D. F. Implementação da Educação Ambiental em escolas: uma reflexão. In: Fundação Universidade Federal do Rio Grande. Revista Eletrônica do Mestrado em Educação Ambiental, v. 4.out/nov/dez 2000.

BRASIL. Ministério da Educação e do Desporto. Secretaria de Educação Fundamental. Referencial Curricular Nacional para a Educação Infantil, Brasília: MEC/SEF, 2013. 3v.: Il.

CARDOSO, Kênia Mesquita Mendes; SILVA, Gil Amaro da. Educação Ambiental nas escolas. 2011. 25 f. TCC (Graduação) - Curso de Biologia, Universidade Estadual de Goiás, Brasília, 2011.

FADINI, P.S.; FADINI, A.A.B. Lixo: desafios e compromissos. Cadernos temáticos de Química Nova na Escola. São Paulo: Sociedade Brasileira de Química. no 1 . maio de 2001. p. 918.

KRISTEN BAILEY. Ehow Brasil. A importância de ensinar a sustentabilidade do planeta às crianças. 2015. A importância de ensinar a sustentabilidade do planeta às crianças. 


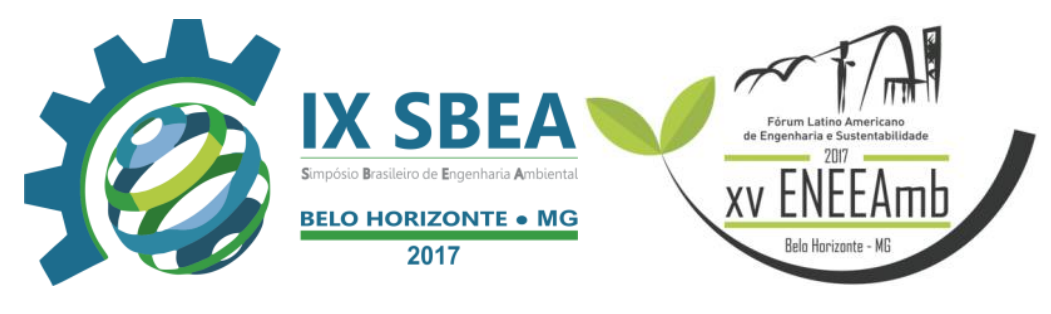

Disponível em: <http://www.ehow.com.br/importancia-ensinar-sustentabilidade-planetacriancas-info_40527/>. Acesso em: 03 jun. 2017.

MACEDO, Maria Alexandra Alves Pinheiro Torres de; RAMOS, Maria da Conceição Pereira. Educação Ambiental e Resíduos Sólidos Urbanos: Caminho para um Futuro Sustentável. Eduser: revista de educação, Porto, v. 7, n. 2, p.41-57, 23 maio 2015. Mensal. Faculdade de Economia da Universidade do Porto. Disponível em: 〈http://www.eduser.ipb.pt>. Acesso em: 04 jun. 2017.

MARÇAL, M. da P.V. Educação ambiental e representações sociais de meio ambiente: uma análise da prática pedagógica no Ensino Fundamental em Patos de Minas - MG. Originalmente apresentado como dissertação de mestrado em Geografia, Universidade Federal de Uberlândia, 2005. 210f. Disponível em: < http://www.cipedya.com/web/ FileDetails.aspx?IDFile=156913> . Acesso em: 04 jun. 2017.

PIVA A.M.; WIEBECK, H. Reciclagem do Plástico. São Paulo, Artibler Editora, 2004. RUY, R. A. V. A Educação Ambiental na Escola. Rio Claro, 2014.

PHILIPPI,Arlindo Jr. PELICIONI, Maria Cecília Focesi. EducaçãoAmbiental e Sustentabilidade. Editora Manole, 2005.

SALGADO, R. G. ; PEREIRA, R. M. R.; SOUZA, S. J. Pela tela, pela janela: questões teóricas e práticas sobre infância e televisão.Cadernos CEDES (Impresso), Campinas, v. 25, n. 65 , p. 9-24, 2005.

SOUZA, Melissa Sommer Miranda de. A Interdisciplinaridade da Educação Ambiental no Ensino Fundamental. 2014. 40 f. Monografia (Especialização) - Curso de Ciências, Diretoria de Pesquisa e Pós-graduação, Universidade Tecnológica Federal do Paraná, Medianeira, 2014. Disponívelem:

<http://repositorio.roca.utfpr.edu.br/jspui/bitstream/1/4382/1/MD_ENSCIE_II_2014_61.pdf>. Acesso em: 06 jun. 2017.

FRIEDRICH, Leidi Cecilia. A Interdisciplinaridade da Educação Ambiental no Ensino Fundamental. 2014. 40 f. Monografia (Especialização) - Curso de Ciências, Diretoria de Pesquisa e Pós-graduação, Universidade Tecnológica Federal do Paraná, Medianeira, 2014. Disponível em: <http://repositorio.roca.utfpr.edu.br/jspui/bitstream/1/4382/1/MD_ENSCIE_II_2014_61.pdf >. Acesso em: 06 jun. 2017. 